\title{
Movilidad y Segregación: Análisis de las Posiciones Ocupacionales en la Localidad de Ciudad Bolívar en Bogotá
}

Mobilidade e segregação: análise das categorias ocupacionais na Localidade de Ciudad Bolivar em Bogotá

Mobility and segregation: analysis of occupational positions in Ciudad Bolivar in Bogotá

Melba Rubiano-Bríñez [a] [iD

[a] Universidad Piloto de Colombia (UPC), Maestría en Gestión Urbana, Facultad de Arquitectura, Bogotá, Colombia.

Cómo citar: Rubiano-Bríñez, M. (2021). Movilidad y Segregación: análisis de las posiciones ocupacionales en la localidad de Ciudad Bolívar en Bogotá. urbe. Revista Brasileira de Gestão Urbana, v.13, e20190372.

https://doi.org/10.1590/2175-3369.013.e20190372

\section{Resumen}

Desde hace algún tiempo, el estudio de la segregación ha sido tema de interés en las ciudades latinoamericanas. En Bogotá, diferentes trabajos académicos giran en torno al examen del fenómeno que se observa en inequidades espaciales con implicaciones sociales y económicas. La segregación como concepto teórico amplio que permite identificar y examinar diferentes fenómenos que se producen sobre el espacio urbano. En ese sentido existen diferentes manifestaciones de la segregación (residencial, socioespacial, étnica, etc.) y, por lo tanto, resulta relevante identificar un aspecto en especial para el abordaje del mismo. El objetivo de este artículo es analizar la segregación socioespacial en Bogotá a partir de las posiciones ocupacionales para lo cual se toma como fuente de información los resultados de la Encuesta Multipropósito 2017. Los resultados de esta revisión documental se confrontaron con la información que arrojó el trabajo de campo desarrollado en la Fase I del proyecto de investigación "Movilidad urbana y el entorno como generadores de ciudadanía" liderado por docentes de la Maestría en Gestión Urbana de la Universidad Piloto de Colombia. Este trabajo se realizó en el barrio El Paraíso de la localidad de Ciudad Bolívar en Bogotá.

Palabras clave: Segregación socioespacial. Posiciones ocupacionales. Ciudad Bolívar. Bogotá.

\section{Resumo}

Há algum tempo, o estudo da segregação tem sido um tópico de interesse nas cidades latino-americanas. Em Bogotá, diferentes trabalhos acadêmicos têm como foco o exame do fenômeno observado nas desigualdades espaciais com implicações sociais e econômicas - a segregação como conceito teórico amplo que permite identificar e examinar os diferentes fenômenos que ocorrem no espaço urbano. Nesse sentido, 
existem diferentes manifestações de segregação (residencial, socioespacial, étnica etc.) e, portanto, é relevante identificar um aspecto específico para abordá-la. 0 objetivo deste artigo é analisar a segregação socioespacial em Bogotá das categorias ocupacionais para as quais os resultados da "Encuesta Multipropósito 2017" são tomados como fonte de informação. Os resultados desta revisão documental foram confrontados com as informações produzidas pelo trabalho de campo desenvolvido na Fase I do projeto de pesquisa "Mobilidade urbana e meio ambiente como geradores de cidadania", liderado por professores do Mestrado em Gestão Urbana da Universidade Piloto da Colômbia. Este trabalho foi realizado no bairro "El Paraíso", na Ciudad Bolívar, em Bogotá.

Palavras-chave: Segregação socioespacial. Categorias ocupacionais. Ciudad Bolívar. Bogotá.

\section{Abstract}

Recently, social segregation issues have gained attention in Latin American cities. Particularly in Bogotá, the literature sheds light on the socioeconomic implications of spatial inequalities. Theoretically, the concept of segregation embodies a multiple scope, which in turn, that allows identifying and examining phenomena occurring in urban contexts. There are different forms of segregation (residential, socio spatial, ethnic, etc.) and therefore, identifying one particular issue to focus on becomes relevant. The aim of this paper is to analyze socio spatial segregation in Bogotá from a labor perspective by drawing on data collected in the "Multipurpose Survey 2017" document. The result found in the latter were correlated with those achieved on the fieldwork carried out during the phase 1 of the research project "Urban mobility and the context as citizenship builders" led by scholars from the Urban Management master program of the Universidad Piloto de Colombia. This study took place in El Paraíso neighborhood, located in the Ciudad Bolívar district in Bogotá.

Keywords: Socio-spatial segregation. Occupational positions. Ciudad Bolívar. Bogotá.

\section{Introducción 1}

La segregación como fenómeno urbano, presente en las ciudades latinoamericanas es tema de interés para entender diferentes problemáticas que afectan a las clases menos favorecidas. En las grandes ciudades se observan niveles de pobreza y desigualdades económicas que inciden sobre las formas en que los más pobres se mueven en la ciudad, no solamente desde el punto de vista de la movilidad residencial sino también la movilidad cotidiana, dada la flexibilidad del contrato laboral debido a la inestabilidad en las formas de contratación que se suman a las crecientes tasas de desempleo. Pobreza y movilidad se relacionan como elementos que inciden sobre la calidad de vida de la población residente en barrios alejados del centro de la ciudad, como señalan Moreno Luna \& Rubiano Bríñez (2014, p. 140):

La movilidad cotidiana tiene una relación directa con la pobreza, entre más pobre sea la persona, mayores problemas y dificultades tendrá para desplazarse, debido, entre otras razones, a la mala y escasa oferta de un transporte público eficiente y rápido, así como por la segregación de sus hogares hacia la periferia de la ciudad, haciendo los viajes diarios mucho más largos en cuanto a distancia.

Bogotá, como capital de Colombia y centro político y administrativo del país, representa un punto de atracción para muchos de los habitantes de otras regiones del país, por lo que concentra la mayor cantidad de población, ratificando la primacía urbana y poblacional de Bogotá (Rubiano-Bríñez \& Eligio-

\footnotetext{
${ }^{1}$ Este artículo es resultado de la investigación denominada Fase I. Movilidad urbana y el entorno como generadores de ciudadanía. Segregación socio- espacial y movilidad. Barrio El Paraíso, Localidad de Ciudad Bolívar - 2019, desarrollada en el marco de la línea de Hábitat, ambiente y territorio de la Maestría en Gestión Urbana y el grupo de investigación Gestión Urbana de la Universidad Piloto de Colombia.
} 
Triana, 2019). Según los resultados del Censo de Población 2018 (DANE, 2019), Bogotá cuenta con 7.412.566 habitantes, lo que representa el $15.4 \%$ de la población total del país. En términos administrativos, la ciudad se encuentra organizada en veinte localidades $y$, a su vez, se subdivide en 112 Unidades de Planeación Zonal UPZ, que constituyen un instrumento de planificación como se señala en el Artículo 49 del Decreto 190 de 2004:

Instrumento de planeación que tiene como propósito definir y precisar el planeamiento del suelo urbano, respondiendo a la dinámica productiva de la ciudad y a su inserción en el contexto regional, involucrando a los actores sociales en la definición de aspectos de ordenamiento y control normativo a escala zonal. (Colombia, 2004).

Adicionalmente, en Colombia se emplea una metodología para clasificar las viviendas en estratos socioeconómicos que se aplica de acuerdo a las características de la vivienda y el entorno, de tal manera que se asignan seis clasificaciones o estratos, siendo 6 el más alto y el estrato 1 corresponde a los estratos más bajos de la población, es decir, los más pobres. La estratificación se utiliza para fijar las tarifas de los servicios públicos y asignar los subsidios:

El estrato socioeconómico se define como el "nivel de clasificación de la población con características similares en cuanto a grado de riqueza y calidad de vida, determinada de manera indirecta mediante las condiciones físicas de la vivienda y su localización”. (DANE, 2015, p. 77).

Tanto la división en UPZ como la clasificación en estratos socioeconómicos sirven como referentes para contextualizar la forma en que se organiza Bogotá. La figura 1 ilustra la ubicación de la UPZ67 - El Lucero, en la Localidad de Ciudad Bolívar ubicada al sur de Bogotá.

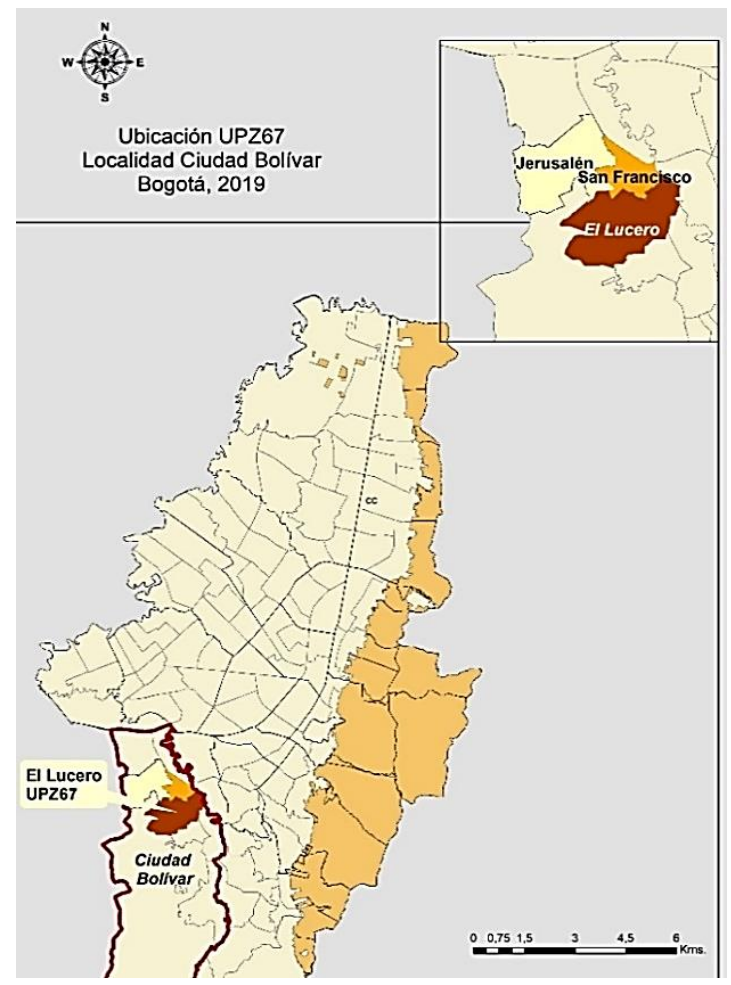

Figura 1 - Mapa localización UPZ67 - El Lucero. Fuente: elaboración propia.

Por otro lado, el Plan Maestro de Movilidad de Bogotá, define el Sistema Integrado de Transporte Público (SITP), como el sistema de transporte de la ciudad. "El SITP es un sistema organizado e integrado 
de diferentes servicios de transporte (Urbano, Especial, Complementario, Troncal, Alimentador y demás modos de transporte que se irán implementado) que buscan el cubrimiento efectivo del transporte en Bogotá" (Transmilenio, 2013).

El sistema de transporte en Bogotá, denominado como Transmilenio, se encuentra organizado esencialmente, alrededor, de lo que se conoce como Bus Rapid Transit (BRT), utilizado también en otras ciudades latinoamericanas como Curitiba en Brasil y Santiago de Chile. Inclusive es un sistema que, en Colombia, ya existe en otras ciudades. En referencia a esto, Moreno Luna (2017, p. 168) afirma:

Bogotá's Bus Rapid Transport (BRT) is widely known. It is a public transport sistem based on high capacity buses segregated from private traffic. The Transmilenio was planned with the purpose of improving the quality and security of the public transport system, and allowed in practice a reduction in travel time and an increase in accessibility to all inhabitants of the city, especially the residents of low income households².

Como complemento al sistema de movilidad, a finales de 2018, entró en funcionamiento el TransmiCable, un sistema de cable aéreo que se implementó en la localidad de Ciudad Bolívar al sur de la ciudad, específicamente, en la UPZ67 El Lucero, zona de estudio del proyecto de investigación. El Transmicable conecta la parte alta de la localidad con una de las estaciones al sur, Portal El Tunal.

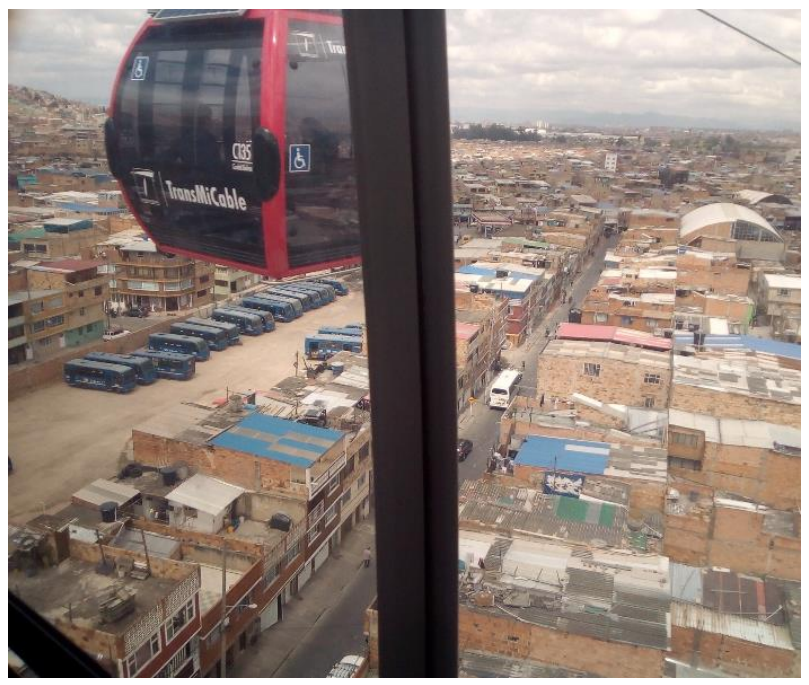

(a)

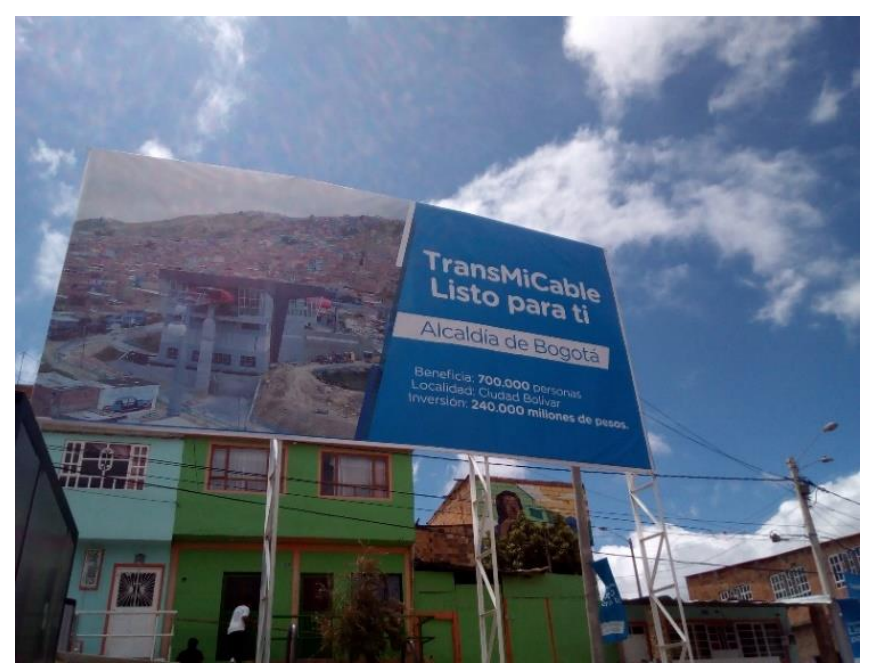

(b)

Figura 2 - Vista del Sistema de transporte en Bogotá - TransmiCable y los buses del SITP. Fuente: Rubiano, M. (2019). (a) Patio de buses del SITP y (b) placa del proyecto en el barrio El Paraíso. Enero 2019.

La explicación previa sirve como punto de partida para señalar cómo diferentes grupos analizados según las posiciones ocupacionales en Bogotá se mueven dentro de la ciudad, lo que conlleva a una interacción entre estratos socioeconómicos diferentes y a concentrar en mayor o menor proporción estos

\footnotetext{
2 El Sistema Transporte Rápido de Autobuses de Bogotá (BRT) es ampliamente conocido. Es un sistema de transporte público basado en autobuses de alta capacidad segregados del tráfico privado. El Transmilenio fue planeado con el propósito de mejorar la calidad y seguridad del sistema de transporte público, y permitió en la práctica una reducción en el tiempo de viaje y un aumento en la accesibilidad para todos los habitantes de la ciudad, especialmente los residentes de hogares de bajos ingresos. (Traducción libre).
} 
grupos, lo que implica que para los más pobres represente recorrer grandes distancias y mayor gasto en tiempo y dinero.

A partir de este breve contexto del sistema de transporte, se plantea la cuestión ¿Cómo la conformación del territorio en una ciudad como Bogotá condiciona de manera directa la forma de desplazamiento y las prácticas de la población en torno a la movilidad cotidiana y su entorno como generador de ciudadanía? Y específicamente, surge otro cuestionamiento que orienta este artículo como pregunta específica del tema de segregación socioespacial ¿Cuál es el diagnóstico de la segregación socioespacial en la UPZ67 de Ciudad Bolívar? Así, se busca analizar la segregación sociolaboral y aportar al entendimiento del fenómeno urbano descrito en términos de la segregación espacial en cuanto al componente laboral.

\section{Aproximación teórica y conceptual: La segregación socioespacial y la movilidad urbana}

El estudio de la segregación socioespacial plantea la necesidad de revisar la noción de segregación en su expresión más básica para incorporar su entendimiento al estudio que se esboza en términos del presente artículo, para lo cual se hace un breve recuento de la evolución del concepto. Posteriormente, se presenta un análisis de los conceptos y variables, centrado en dos estudios reseñados en el estado del arte, a partir de los cuales se construye el camino metodológico seleccionado.

\section{Segregación urbana}

Salas \& Solano (1993), analizan los antecedentes del concepto de segregación urbana y elaboran una revisión de los autores clásicos, lo que se considera pertinente como preámbulo de esta investigación. Para ello, señalan tres autores que han aportado a la construcción del concepto: Lefebvre, Lojkine y Castells.

Lefebvre relaciona la segregación con "la organización del espacio en sociedades capitalistas", (Salas \& Solano, 1993, p. 18). En este sentido, destaca tres elementos como condicionantes de la producción social: la transformación del espacio como mercancía; el acceso socialmente diferenciado al espacio urbano y, la apropiación simbólica del espacio, (Salas \& Solano, 1993). Por lo que se considera que, el segundo elemento se relaciona con el propósito del estudio de la segregación en el contexto de este escrito.

Salas \& Solano, también, citan a Jean Lojkine, quien considera que la segregación urbana se relaciona en términos del "acceso desigual de las diferentes clases sociales a la ciudad" (Salas \& Solano, 1993, p. 19). Es decir, se entiende que tiene relación con el acceso diferenciado a los bienes de consumo colectivo (equipamientos y la infraestructura pública) y su localización espacial en la ciudad. Señala, además, dos aspectos en los que se presenta la segregación urbana: en el transporte y en la vivienda, en relación a los mayores costos en los cuales debe incurrir la población para movilizarse desde la residencia hasta el lugar de trabajo. Este último punto se considera relevante por cuanto vincula el tema analizado directamente, es decir, a partir del análisis propuesto en el que se busca revisar la segregación con base en las posiciones ocupacionales de la Encuesta Multipropósito 2017 (EM2017) y confrontarlos con los resultados del trabajo de campo desarrollado en Ciudad Bolívar para analizar la segregación con base en los índices calculados.

A partir de lo mencionado por Castells (2014) se reconoce a la segregación urbana como una forma de analizar el proceso de urbanización y, por lo tanto, los efectos en la vida cotidiana de la población. Específicamente, Castells (2014, p. 32) señala que: 
Por otra parte, la uniformización de una masa creciente de población en cuanto a la posición que ocupan en la producción (asalariados) se ve acompañada de una diversificación de los niveles y de una jerarquización en el seno mismo de esta categoría social, lo que trae como resultado en el espacio una auténtica segregación en términos de estatuto, separando y "marcando" los diferentes sectores residenciales, que se esparcen en un amplio territorio, diferenciado desde el punto de vista simbólico.

Es decir, que la segregación se evidencia a partir del análisis realizado desde el punto de vista de la posición laboral que se reparte a lo largo de la ciudad, con implicaciones en la calidad de vida de la población, dada las necesidades de desplazamientos, es decir, la movilidad hacia otros lugares de la ciudad por razones de trabajo. Así, se entiende que, según la organización de la ciudad, se van distribuyendo en el espacio los grupos sociales $\mathrm{y}$, por lo tanto, las personas que llevan a cabo sus diferentes trabajos.

\section{Movilidad urbana}

De acuerdo con Litman (2008), uno de los aspectos que tienen en cuenta los planificadores urbanos al momento de analizar las políticas públicas tiene que ver con lo que denomina la calidad de la accesibilidad que tienen los grupos sociales al interior de la ciudad y cómo se comparan entre sí, especialmente, en lo que atañe a los grupos desfavorecidos, dada la necesidad de entender que la forma en que las personas se movilizan dentro de una ciudad no es homogénea.

Esto se complementa con la definición de Jans (2017, p. 9) quien señala que los diferentes desplazamientos al interior de la ciudad requieren el "uso de distintos tipos de transporte colectivo" que inciden en la calidad de vida de las personas y, en consecuencia, se propende por optimizar los desplazamientos cotidianos entre la vivienda y el trabajo. En este sentido, la movilidad urbana en términos de este escrito, se entiende como los desplazamientos cotidianos que realizan los residentes de una ciudad, acorde con las necesidades y las actividades que ellos desarrollan en el espacio urbano.

\section{Movilidad urbana y segregación}

En una ciudad como Bogotá con una población cercana a los 8 millones de habitantes, con una tasa de desempleo a marzo de 11,8\% (DANE, 2020), es de mencionar que la mayor parte de esta población reside en la periferia y se encuentra alejada del centro de la ciudad y de otras donde se encuentran las posibilidades de emplearse. Además, corresponde a la población de los estratos más pobres y, por tanto, la movilidad impacta sobre los gastos diarios en que deben incurrir, por lo que, es de considerarse que las dificultades de movilidad se relacionan con la segregación socioespacial, dado que el sistema de transporte existente genera mayores costos en cuanto a tiempos de desplazamiento y en cuanto al dinero que deben gastar.

De esta manera, los inconvenientes en el acceso y la necesidad de moverse en la ciudad debido a las condiciones de informalidad y la flexibilización del contrato laboral, se convierten en condiciones que generan segregación debido a las distancias que tienen que recorrer a diario entre el lugar de trabajo y el sitio donde residen, lo que incide de manera directa en la calidad de vida de la población y aumentan las condiciones de segregación derivadas de la ubicación periférica y los largos trayectos que deben recorrer a diario. Como señalan Beuf \& García (2016, p. 415), el problema del transporte y las condiciones de "la parte sur de Bogotá que está muy congestionada y alejada del centro metropolitano donde se ubican la mayor parte de los empleos", debido a estas pésimas condiciones de accesibilidad que acentúan la problemática de la segregación socio espacial. En este sentido, se reconoce que la segregación 
socioespacial se relaciona con las dificultades para lograr una adecuada incorporación al mercado laboral “debido a las diferencias espaciales en las que reside la población” Moreno (2017, p. 37).

\section{El estado del arte de la medición de la segregación en Bogotá}

En términos de la medición de los indicadores de segregación, se encuentran varios estudios realizados por iniciativa institucional como los realizados por la Secretaría Distrital de Planeación entre los cuales está "Segregación socioeconómica en el espacio urbano de Bogotá" (2012); "La estratificación en Bogotá: impacto social y alternativas para asignar subsidios" (2016) que recopila tres trabajos pero con mayor interés en el capítulo denominado "Caracterización y medición de la segregación social y escolar en Bogotá y la región". Por otro lado, desde el ámbito académico se destaca el trabajo de Arbeláez (2017), el cual se tomó como referencia en la investigación por ser el más reciente y que presenta con más detalle la explicación de la parte metodológica.

Desde el punto de vista metodológico, el trabajo de la SDP (2012) utiliza la metodología para el cálculo de indicadores de segregación citado por Linares \& Lan (2007) que plantea tres enfoques:

- Comparación de grupos poblacionales diferentes, denominado enfoque de separación de grupos. (Ej. población pobre vs población no pobre; población ocupada y desocupada). Se calculan tres indicadores: Igualdad (índice de Duncan); Interacción (índice de Bell) y Concentración.

- Diversidad de la población a partir de las características de estudio, desarrolla el cálculo de: Índice de Segregación Residencial y el Índice Multivariado de Segregación Socieconómica.

- Relación de las características de la población con la ubicación en el espacio geográfico que ocupan.

El cálculo de los índices mencionados, se realiza a partir de las fuentes de información suministrada por: la Encuesta de Calidad de Vida, la Encuesta Multipropósito de Bogotá y las Bases Catastrales (2004 y 2011), (SDP, 2012, p. 17). Lo más destacado de este último documento es el análisis realizado que facilitó contar en su momento con datos actualizados que permitió identificar las localidades de Bogotá con mayor nivel de segregación, de acuerdo con las variables definidas.

Un segundo estudio significativo acerca de la medición de la segregación en Bogotá se encuentra en Fresneda et al. (2016), denominado Caracterización y medición de la segregación social y escolar en Bogotá y la región. En dicho estudio, según Fresneda et al. (2016, p. 62), "la segregación es una expresión de la desigualdad social que consiste en la separación de determinados grupos sociales de los otros". El documento revisa los antecedentes teóricos del concepto de segregación y presenta los casos específicos de estudios en el ámbito internacional a partir de los casos de París, Chicago y Rio de Janeiro, además, presenta una síntesis de los estudios previos sobre la segregación urbana en Bogotá donde deja explícito que las investigaciones precedentes se han enfocado, principalmente, en "el aspecto residencial, en qué tan separados habitan unos grupos de otros" (Fresneda et al., 2016, p. 72). Sin embargo, advierte que también es necesario analizar la accesibilidad en aras de identificar procesos relacionados con la forma de moverse en la ciudad por razones de trabajo, recreación o al lugar de residencia. La parte metodológica del documento de Fresneda et al. (2016) se basa en la "medición y caracterización de la segregación habitacional en Bogotá" haciendo uso de las categorías sociales definidas en términos de las relaciones laborales que determina el acceso a los recursos económicos y sociales. Dicha investigación, analiza la segregación residencial con base en la información de la Encuesta Multipropósito de Bogotá de 2014, a partir de la cual define las categorías socio-ocupacionales, a saber: obreros, trabajadores domésticos, empleados, profesionales y técnicos, directivos, trabajadores independientes, campesinos y otros trabajadores. Los resultados muestran que "la composición de los trabajadores en la geografía de la ciudad es altamente heterogénea" (Fresneda et al., 2016, p. 91), lo que representa las desigualdades sociales que se verifican en las diferentes localidades de Bogotá. De acuerdo con los resultados obtenidos, Fresneda encontró que la categoría que presenta un índice de segregación más elevado corresponde a los 
trabajadores domésticos y los obreros no calificados que se ubican principalmente en las localidades de origen popular de Bosa, Kennedy y Ciudad Bolívar. Por otro lado, la posición laboral menos segregada son los empleados que, según el estudio es la más numerosa en la configuración social de la ciudad.

Finalmente, se reseña el trabajo de Arbeláez (2017) por su amplia revisión del estado del arte sobre la medición de la segregación y el análisis cuantitativo en el que, desde el punto de vista metodológico, es relevante porque explica los principales indicadores para la medición de la segregación utilizadas, a saber: el índice de segregación, el índice de disimilitud, el índice de interacción y el coeficiente de localización. Esta descripción brinda algunos de los elementos que se acogen para el presente artículo que se consideran relevantes como aporte teórico, conceptual y metodológico.

En términos de la presente investigación, se atiende la conceptualización que presenta Arbeláez (2017, p. 427), citando a Préteceille (2006), en la que afirma que: "la segregación se define como la distribución desigual de los grupos sociales en el espacio urbano". Así, dentro de la revisión teórica de Arbeláez (2017), reseña a Préteceille, Duncan \& Duncan y destaca a Massey \& Denton, cuyo trabajo considera el más completo porque explica cada índice y destaca la taxonomía de las "diferentes dimensiones de la segregación" Arbeláez (2017, p. 427), así:

- De igualdad: distribución de los grupos de población en el espacio urbano.

- De exposición: que mide el contacto potencial y la probabilidad de interacción entre los diferentes grupos.

- De concentración: se relaciona con el número de individuos de un grupo en una superficie definida.

- De agrupamiento: se refiere a la agrupación continua de grupos de población.

- Centralización: tiene que ver con la localización cercana de un grupo de población del centro de la ciudad.

Desde el punto de vista metodológico, Arbeláez (2017) explica en detalle el cálculo de los índices de segregación realizados en la zona metropolitana de Bogotá, con base en los datos del censo 2005 y de la encuesta multipropósito 2014. Luego, a partir de los resultados obtenidos obtuvo las estadísticas de las posiciones ocupacionales en el ámbito de las 20 localidades de Bogotá y analizó las implicaciones en términos de las interacciones laborales con la región metropolitana. En el análisis de la segregación urbana, Arbeláez explica el coeficiente de localización que "mide la proporción de trabajadores de una posición específica dentro del grupo de trabajadores de la localidad, sobre la proporción de trabajadores de una posición específica en el total de trabajadores de una ciudad" (Arbeláez, 2017, p. 436.) Debido al aporte a la comprensión de este indicador, a continuación, se transcribe lo más útil para los propósitos de este artículo:

Estudiar la segregación laboral es relevante, entre otras razones, porque un movimiento del tipo de trabajadores en una localidad puede configurar un orden residencial urbano diferente. Por lo tanto, es importante analizar la segregación laboral de una sociedad por su relación intrínseca con los niveles de desigualdad y de inclusión por la composición socioeconómica de un determinado territorio y la manera como se localizan los agentes económicos. (Arbeláez, 2017, p. 428).

Otra conclusión relevante y que el autor deja como sugerencia:

realizar un análisis de la segregación laboral teniendo en cuenta la movilidad de los trabajadores, es decir, el lugar donde viven y el lugar en donde trabajan. Los flujos de población entre localidades pueden otorgar una mejor perspectiva a la segregación laboral si se tiene en cuenta que, a diferencia de las clases más altas, para los demás grupos los lugares de trabajo no se encuentran principalmente en las zonas donde predominan sus residencias. (Arbeláez, 2017, p. 461). 
Se reitera que se acoge la propuesta teórica y metodológica del trabajo de Arbeláez (2017) porque se considera uno de los trabajos más recientes y más completos en la descripción del enfoque investigativo y en la revisión de los referentes teóricos.

\section{Metodología}

A partir de un enfoque mixto, la investigación se basó en datos cuantitativos (Encuesta Multipropósito 2017, DANE, 2018) y del Observatorio de Movilidad 2017 (SDM, 2017) y, datos cualitativos con base en el trabajo de campo de la investigación. . Se emplearon técnicas de recolección como la Encuesta a usuarios de Transmicable. Se calculó el coeficiente de localización e índice de segregación con base en los resultados de la Encuesta Multipropósito 2017; Cálculo del índice de Segregación según la metodología descrita por Arbeláez (2017, p. 434 y ss) y datos de las EM2017 y 2015 y como variable principal se determinó el análisis de la posición ocupacional.

La Encuesta Multipropósito es un instrumento técnico que unifica los contenidos temáticos de la Encuesta de Capacidad de Pago y la Encuesta de Calidad de Vida que abarca diferentes "aspectos de cobertura, calidad y gasto de los hogares en servicios públicos domiciliarios, mercado laboral y condiciones de vida a nivel de la ciudad" DANE (2018, p. 2). A la fecha se ha realizado tres mediciones: en 2011, 2014 y 2017 y, en cada versión se ha ido ampliando la cobertura de aplicación. El objetivo es "obtener información para caracterizar la actividad económica de la población en Bogotá y municipios de estudio. Indagar sobre la participación de los integrantes del hogar en el mercado laboral, ingresos, horas laboradas, empleo secundario, actividades no remuneradas y otras características" EM2017. Para el ejercicio realizado se tomaron los datos disponibles del capítulo Fuerza de trabajo de la Encuesta Multipropósito 2017.

Para el cálculo del Coeficiente de Localización se empleó la fórmula (Ecuación 1):

$Q L=\frac{\frac{X i}{t i}}{X / T} ;(0, \infty)$

Los valores del coeficiente de localización van desde cero a infinito, de tal manera que cuando es mayor que uno, significa una concentración de la posición ocupacional en dicha ubicación y cuando es menor de uno, hay subrepresentación de ese grupo en una determinada zona.

A efectos de la interpretación, se entiende que, los valores van entre 0 y 1 , donde se muestra la no existencia de segregación y la segregación total, respectivamente. (Arbeláez, 2017, p. 437).

Para el Índice de Segregación se calculó con la Ecuación 2:

$I S=\frac{1}{2} \sum_{i=1}^{n}\left(\frac{X_{i}}{X}-\frac{t_{i}-X_{i}}{T-X}\right) ;[0,1]$

Siguiendo los lineamientos metodológicos de Arbeláez (2017), en el ejercicio realizado se tuvieron en cuenta las siguientes posiciones ocupacionales:

- Obreros

- Patrones

- Trabajadores por cuenta propia

- Empleados domésticos

- Trabajadores sin remuneración. 


\section{Resultados}

Con base en la información tomada de la Encuesta Multipropósito 2017, se calculó el coeficiente de localización y el índice de segregación, de acuerdo con las posiciones ocupacionales, cuyos resultados se compararon con los de Arbeláez (2017), los cuales se presentan a continuación. Más adelante, se describen los resultados de la encuesta aplicada a los usuarios de Transmicable en la UPZ 67, El Lucero:

\section{Cálculo del Coeficiente de localización - Localidad Ciudad Bolívar}

A partir de los datos de Arbeláez (2017), el resultado del coeficiente de localización para Ciudad Bolívar, indica que los empleados domésticos y los obreros tienen una sobrerrepresentación frente a las demás posiciones ocupacionales. Es decir, hay una concentración en la localidad de estos grupos.

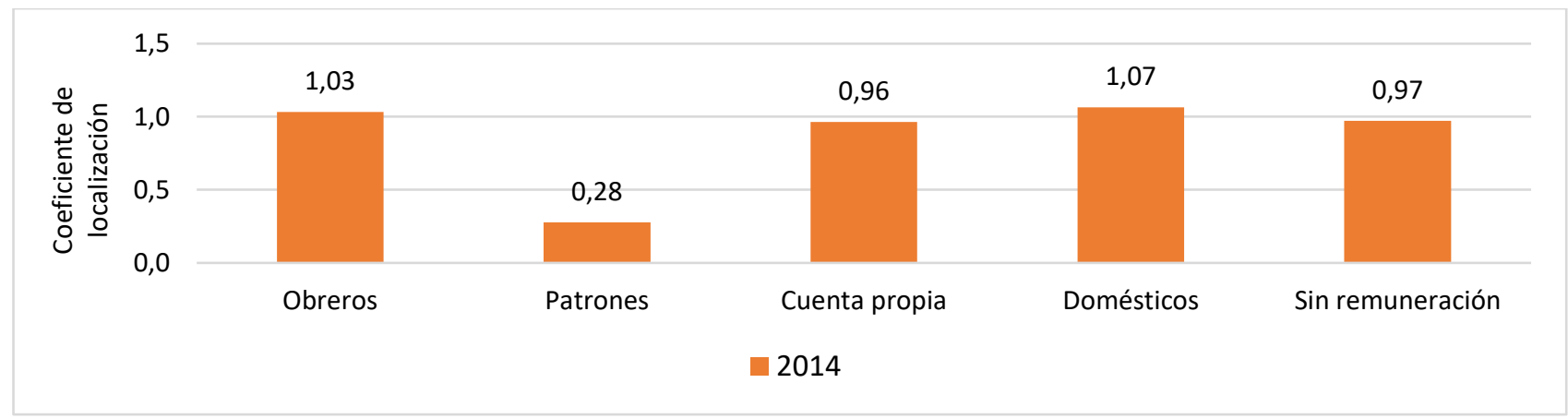

Figura 3 - Coeficiente de localización en Ciudad Bolívar según EM2014. Fuente: elaboración propia con base en Arbeláez

(2017).

Luego, se calculó el Coeficiente de Localización con base en la EM2017 y se encontró que en la UPZ67 El Lucero, la mayoría de las posiciones ocupacionales corresponde a "empleados sin remuneración", en comparación con las otras UPZ de la misma localidad, San Francisco y Jerusalén. Lo que se puede explicar porque corresponden a personas que trabajan en negocios familiares como tiendas, restaurantes, entre otros.

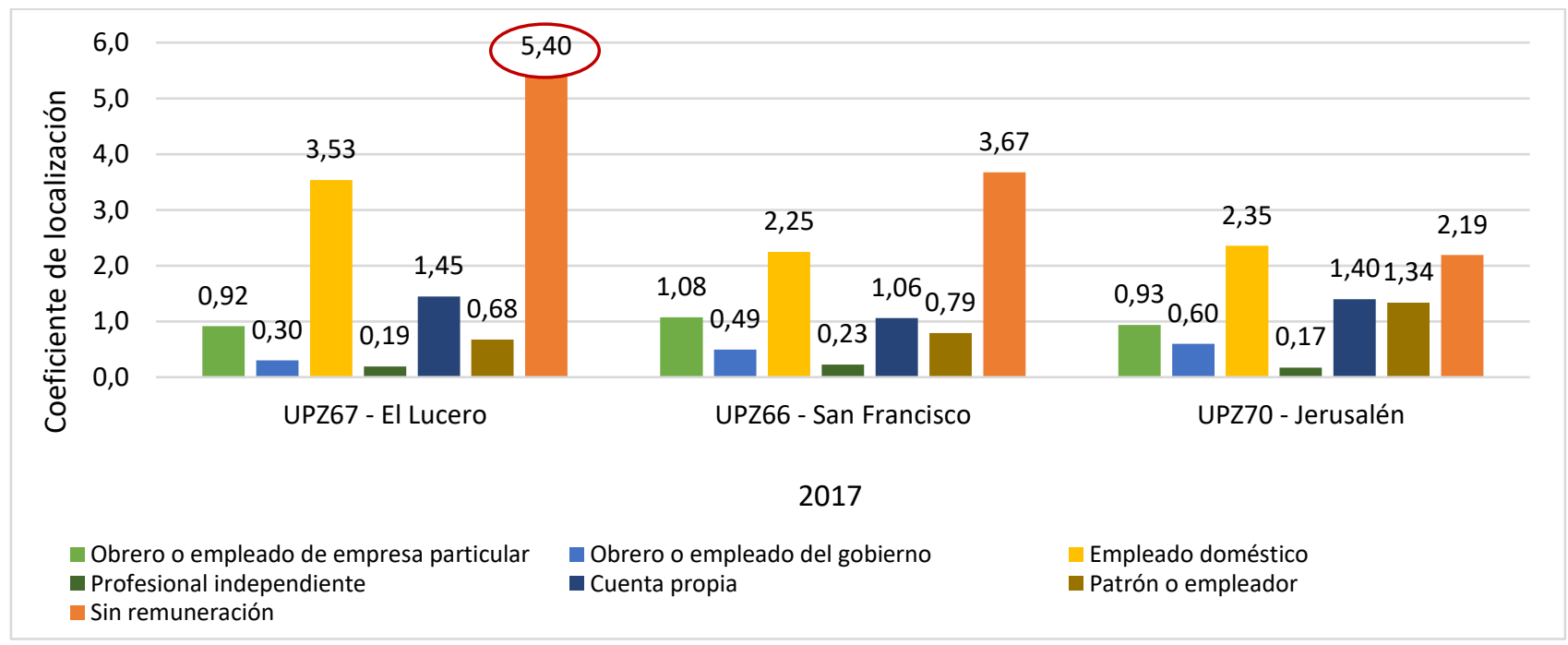

Figura 4 - Coeficiente de localización en UPZ67 de Ciudad Bolívar, según EM2017. Fuente: elaboración propia con base en la EM2017. 


\section{Índice de Segregación}

El índice de segregación calculado con base en la EM2017, en comparación con el índice calculado por Arbeláez (2017), muestra que los obreros y los “cuenta propia” tenían una posición más cercana. Además, los empleados domésticos y los obreros están menos segregados por encontrarse distribuidos por toda la ciudad, dado el tipo de labor que realizan. Teniendo en cuenta que donde "los valores cercanos a cero indican una distribución uniforme de la población y desigual cuando son más cercanos a uno" (Arbeláez, 2017, p. 454).

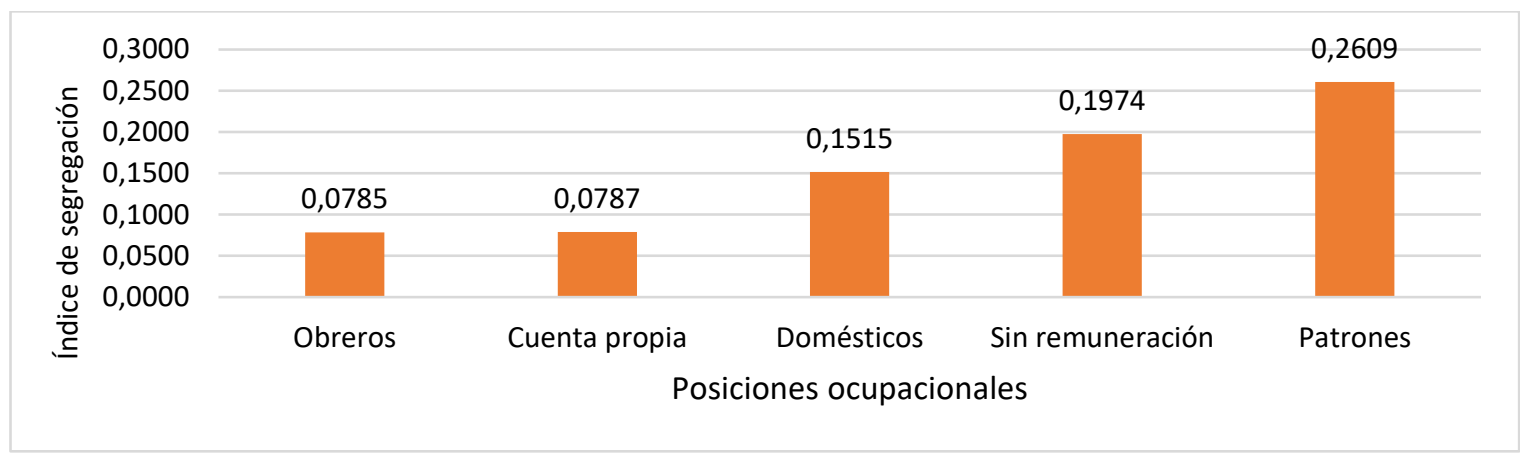

Figura 5 - Índice de Segregación según EM2014. Fuente: Elaboración propia con base en Arbeláez (2017).

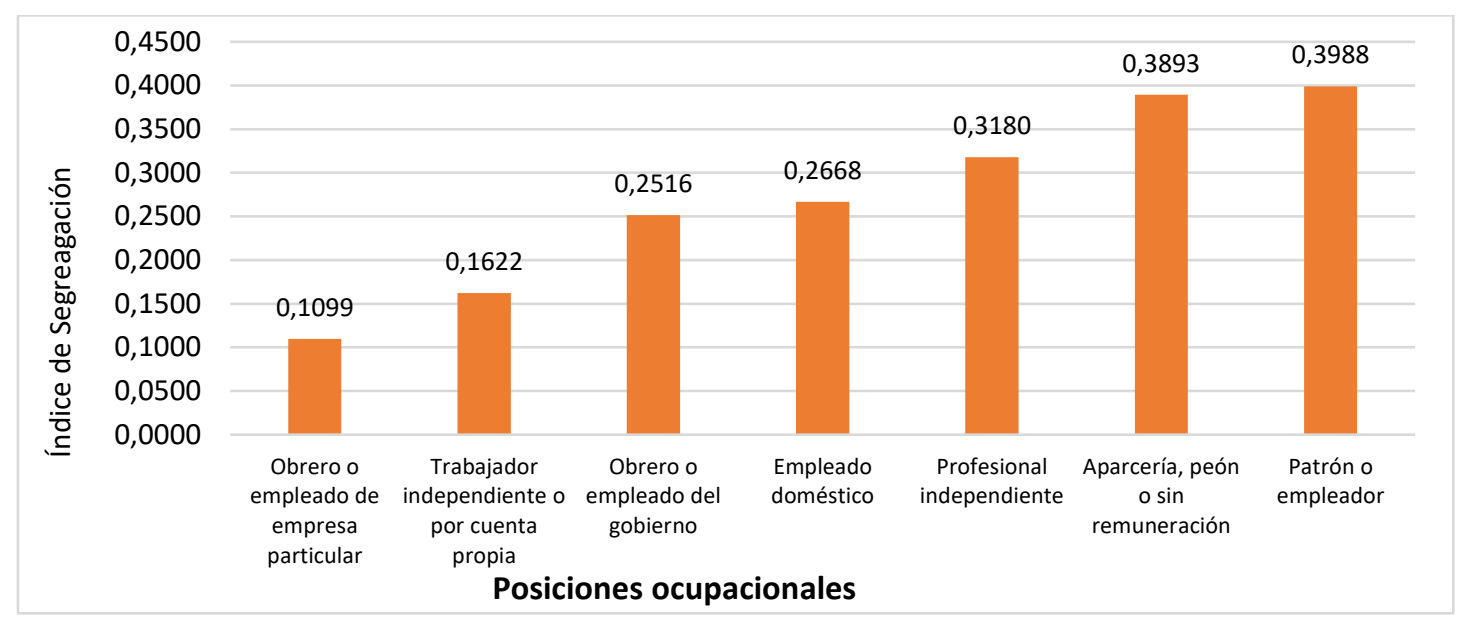

Figura 6 - Índice de Segregación según EM2017. Fuente: elaboración propia con base en la EM2017.

Las cifras muestran que para 2014 y 2017, la posición ocupacional que corresponde a "patrones" tiene un IS más elevado, lo que significa que el mayor nivel de segregación se debe a la tendencia a autosegregarse. Es decir, pueden localizarse donde gusten porque cuentan con los recursos económicos para escoger la localización que deseen. En cambio, los trabajadores sin remuneración tienden a estar más segregados por estar agrupados en la localidad sin que muestren una tendencia a moverse en el resto de la ciudad. Por otro lado, los obreros corresponden a la posición ocupacional menos segregada por cuanto, se considera que se encuentran repartidos por toda la ciudad. En últimas, la comparación de ambas mediciones la tendencia es similar, mostrando un incremento entre un período y otro. 
Tabla 1 - Comparativo Índice de Segregación según posiciones ocupacionales

\begin{tabular}{lllc}
\hline Arbeláez 2017, Resultados EM2014 & Rubiano 2019, Resultados EM2017 \\
\hline Obreros & 0.0785 & Obreros & 0.1099 \\
Patrones & 0.2609 & Patrones & 0.3988 \\
Cuenta propia & 0.0787 & Cuenta propia & 0.1662 \\
Domésticos & 0.1515 & Domésticos & 0.2668 \\
Sin remuneración & 0.1974 & Sin remuneración & 0.3893 \\
\hline
\end{tabular}

Fuente: Arbeláez (2017), con base en la EM2014; Elaboración propia con base en la EM2017.

\section{Resultados de la encuesta Segregación socio espacial y movilidad UPZ67, El Lucero, Localidad de Ciudad Bolívar}

Se colige que los obreros y la posición "cuenta propia", son los que más necesitan moverse por la ciudad dadas sus actividades, de tal manera que coincide con los resultados del trabajo de campo realizado, que señalan que el 53\% son empleados y 22\% a cuenta propia (ver Figura 7), y de estos, el 59\% de los entrevistados, utiliza el Sistema Transmicable por motivos laborales.

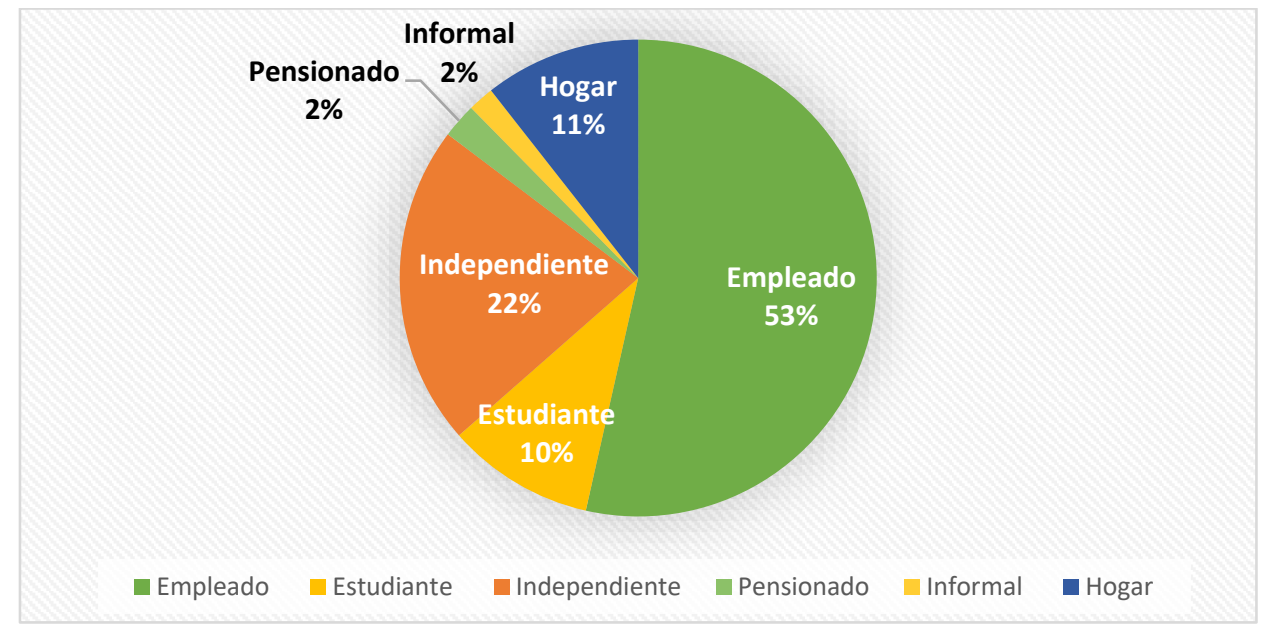

Figura 7 - Distribución porcentual de los usuarios de Transmicable. Fuente: Elaboración propia con base en los resultados del trabajo de campo investigación MGU, 2019.

Según la interpretación de los resultados de los índices calculados por Arbeláez (2017, p. 434), en la UPZ 67 según el índice de localización la mayor parte de los residentes corresponde a la actividad laboral servicios domésticos, empleados por cuenta propia y trabajador de empresa familiar sin remuneración, lo que implicaría que ¿no se movilizan tanto fuera de la localidad, o de la UPZ, como se podría pensar?

Para responder a este cuestionamiento se debe empezar por señalar que El Paraíso donde se ubica una de las estaciones del Transmicable, es un barrio consolidado que se encuentra integrado al Sistema de Transporte de la ciudad, pero que, sin embargo, dadas las condiciones socioeconómicas de los residentes, se presentan dificultades por el acceso a mejores condiciones laborales, lo que produce que realicen actividades "por cuenta propia" o en servicios domésticos, principalmente.

Dado el crecimiento de la ciudad y su extensión hacia la zona sur, donde especialmente, se ubican las clases más pobres, se produjo una ampliación del sistema de transporte y, primordialmente, con la construcción del Transmicable, mejoró la prestación del servicio y redujo tiempos de desplazamiento, según se deduce de la encuesta aplicada a los usuarios (ver Figura 8). Para el 91\% de los encuestados, la implementación del Trasmicable les permitió mejorar su calidad de vida, en términos de optimizar los tiempos de desplazamiento y la calidad del transporte. También, se perciben mejoras en la seguridad alrededor de las estaciones, mantenimiento de andenes, construcción de parques y pinturas de fachadas 
de las casas. Esto último, como resultado de un programa del gobierno local que entregó los insumos para los residentes.

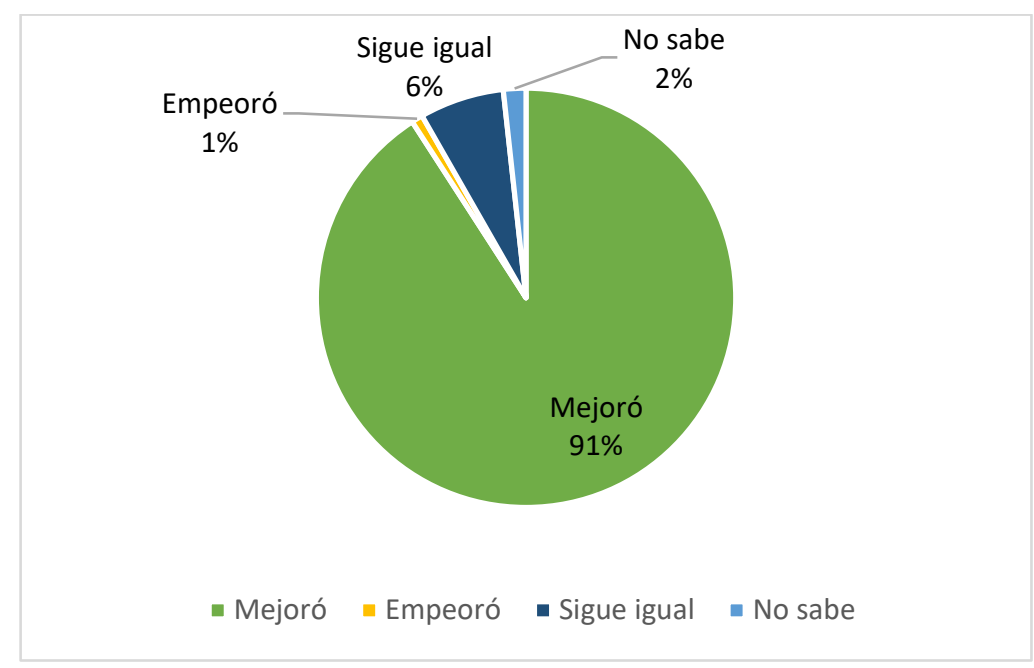

Figura 8 - Mejoramiento de tiempo de desplazamiento después de TMC. Fuente: Elaboración propia con base en los resultados del trabajo de campo investigación MGU, 2019.

En cuanto al entorno de la Estación de Transmicable en el barrio El Paraíso, se constató la percepción de más presencia de comercio y de vendedores ambulantes (informales) en el espacio público.
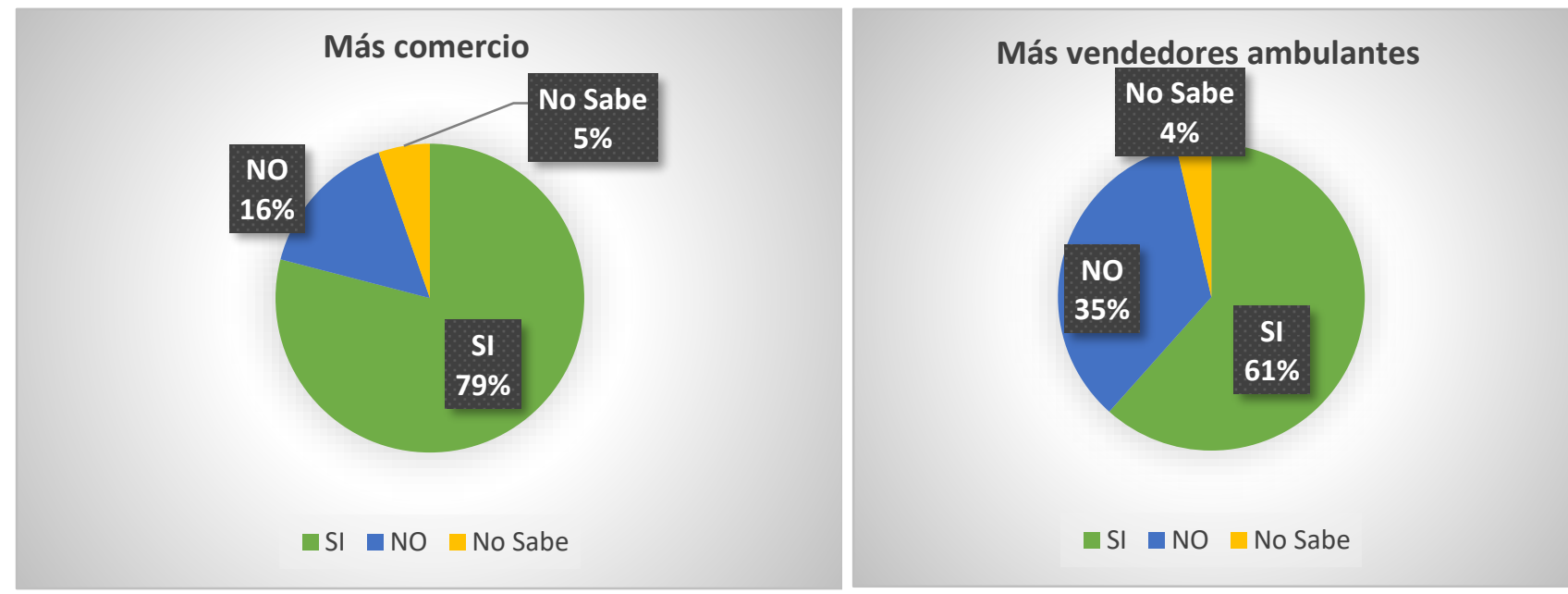

Figura 9 - Percepción de los residentes de incremento de la dinámica del sector de TMC. Fuente: Resultados del trabajo de campo investigación MGU, 2019.

Como complemento, se analizó la información del Observatorio de Movilidad 2017, en el cual, de acuerdo con la Figura 10, los que más se movilizan en Bogotá, son los estratos 1 y 2, es decir, los estratos con mayor prevalencia en Ciudad Bolívar y en la UPZ 67, lo que reafirma el planteamiento inicial que las clases más pobres son las que tienen mayor necesidad de moverse en la ciudad y, por lo tanto, demandan un mejor servicio de transporte. 


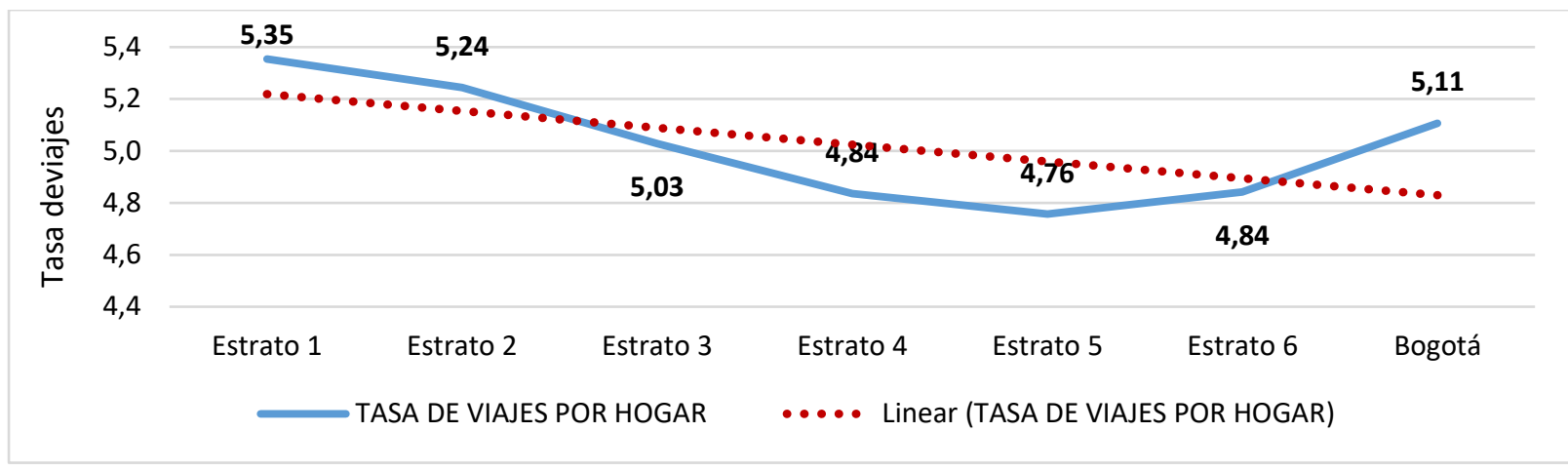

Figura 10 - Tasa de viajes por hogar por estrato socioeconómico en Bogotá. Fuente: elaboración propia con base en la información del Observatorio de la Movilidad 2017.

Según la Figura 11, se observa que la mayor tasa de viajes por persona durante los días hábiles, según la ocupación, se debe, principalmente, por motivos de trabajo.

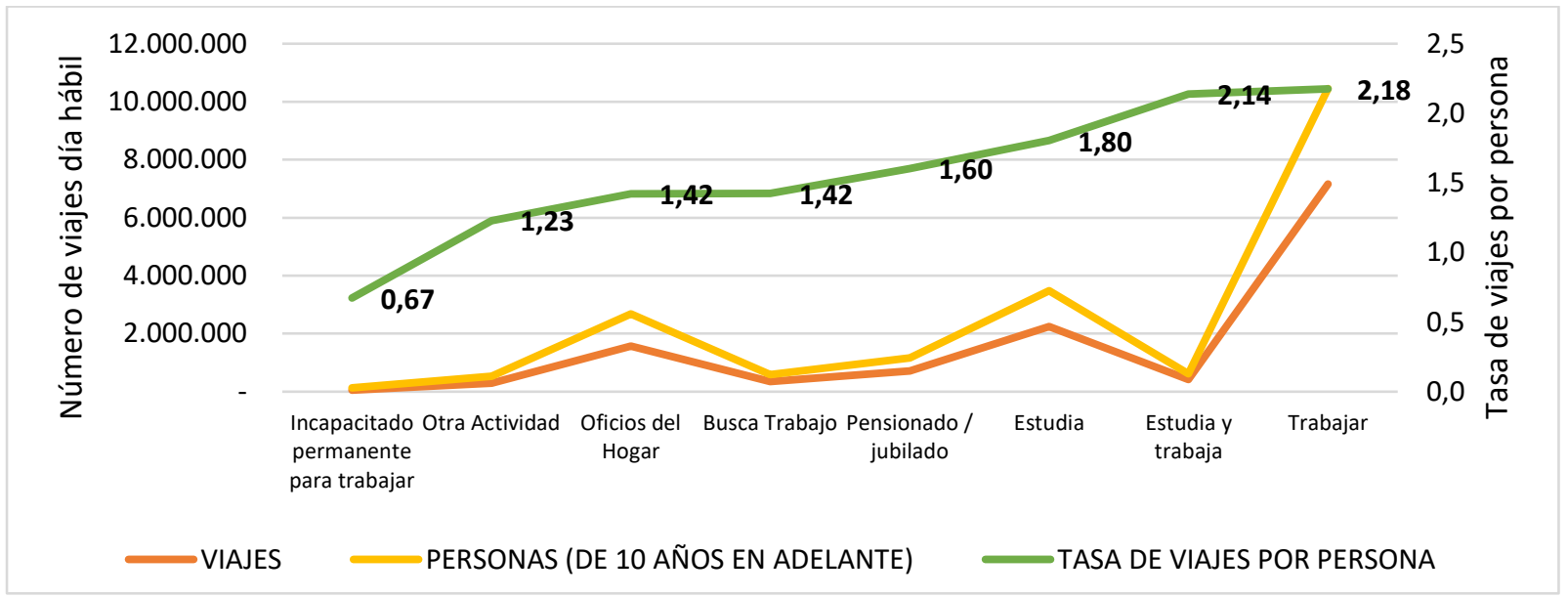

Figura 11 - Tasa de viajes por persona en día hábil según ocupación. Fuente: elaboración propia con base en la información del Observatorio de la Movilidad 2017.

En la Figura 12 se observa la cantidad de viajes generados en cada una de las UPZ en Ciudad Bolívar, con el propósito de comparar y destacar que, después de Ismael Perdomo, la UPZ67 El Lucero es la segunda que más genera y atrae viajes durante todo el día, lo que representa una gran dinámica en la movilidad de sus habitantes. 


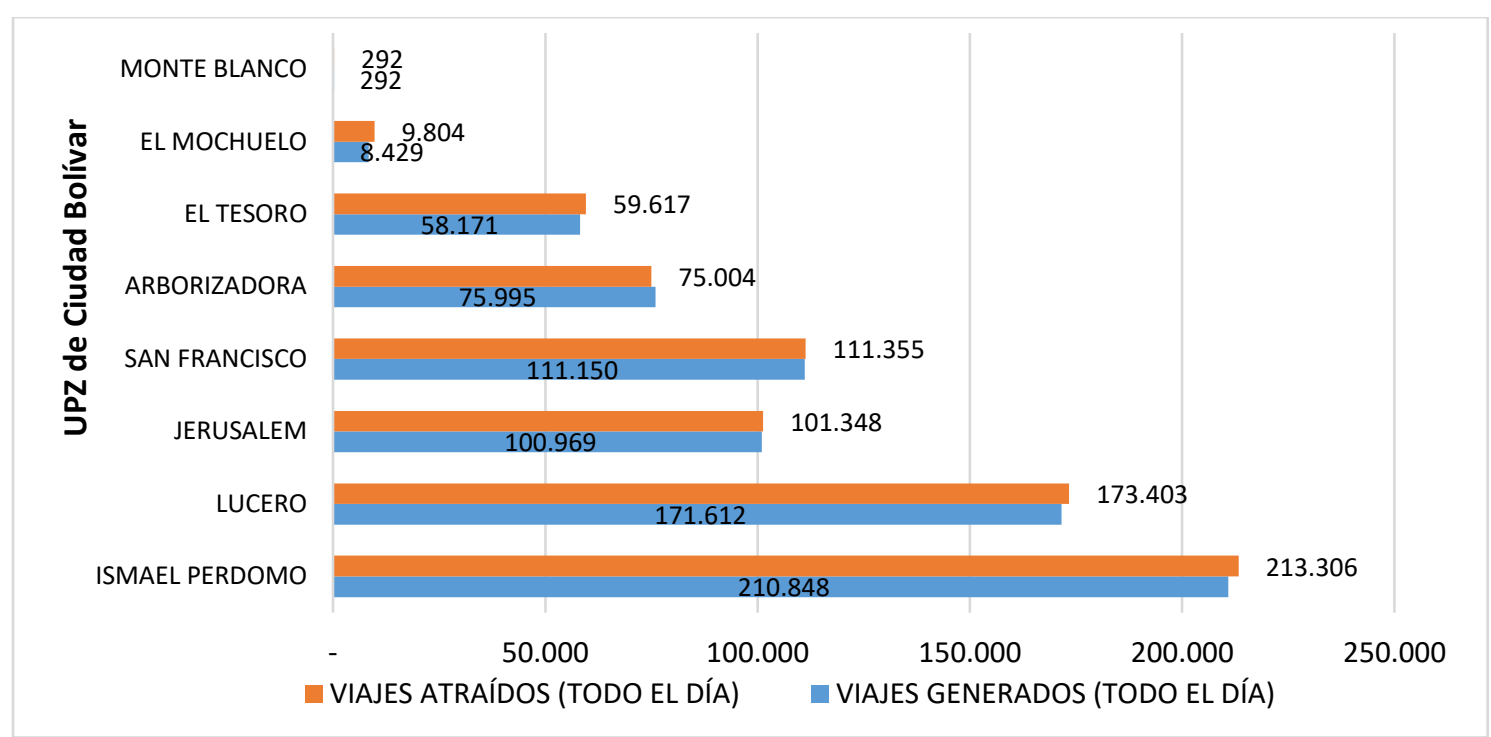

Figura 12 - Viajes generados y atraídos por UPZ en Ciudad Bolívar. Fuente: elaboración propia con base en la información del Observatorio de la Movilidad 2017.

En suma, los resultados de la encuesta aplicada a los residentes, dejan percibir que, con la implementación del Transmicable, hubo mejoras en la calidad del servicio, los tiempos de desplazamiento y la seguridad en el entorno de las estaciones. Sin embargo, consideran que hace falta mejorar la seguridad en el resto del sistema, es decir, después que salen del Transmicable y hacen el intercambio hacia la integración con los buses del SITP y las troncales de Transmilenio.

\section{Discusión}

El análisis conjunto de los resultados obtenidos de la encuesta aplicada a los residentes de la UPZ67 El Lucero de la localidad de Ciudad Bolívar donde se ubica el Transmicable; el cálculo del coeficiente de localización y del índice de segregación con base en los datos de la Encuesta Multipropósito 2017 y los datos del Observatorio de la Movilidad 2017 evidencia que los sectores populares son los que más les afecta la movilidad cotidiana, debido a las distancias que deben recorrer para llegar a sus lugares de trabajo, así mismo, son los que más se movilizan dentro de la ciudad. La Localidad de Ciudad Bolívar, concentra la mayor parte de los obreros y empleados domésticos, lo que es coherente con el índice de segregación que da como resultado que estas dos posiciones ocupacionales, precisamente sean las menos segregadas por encontrar su trabajo en diferentes zonas de Bogotá y deben interactuar con otros grupos poblacionales. 


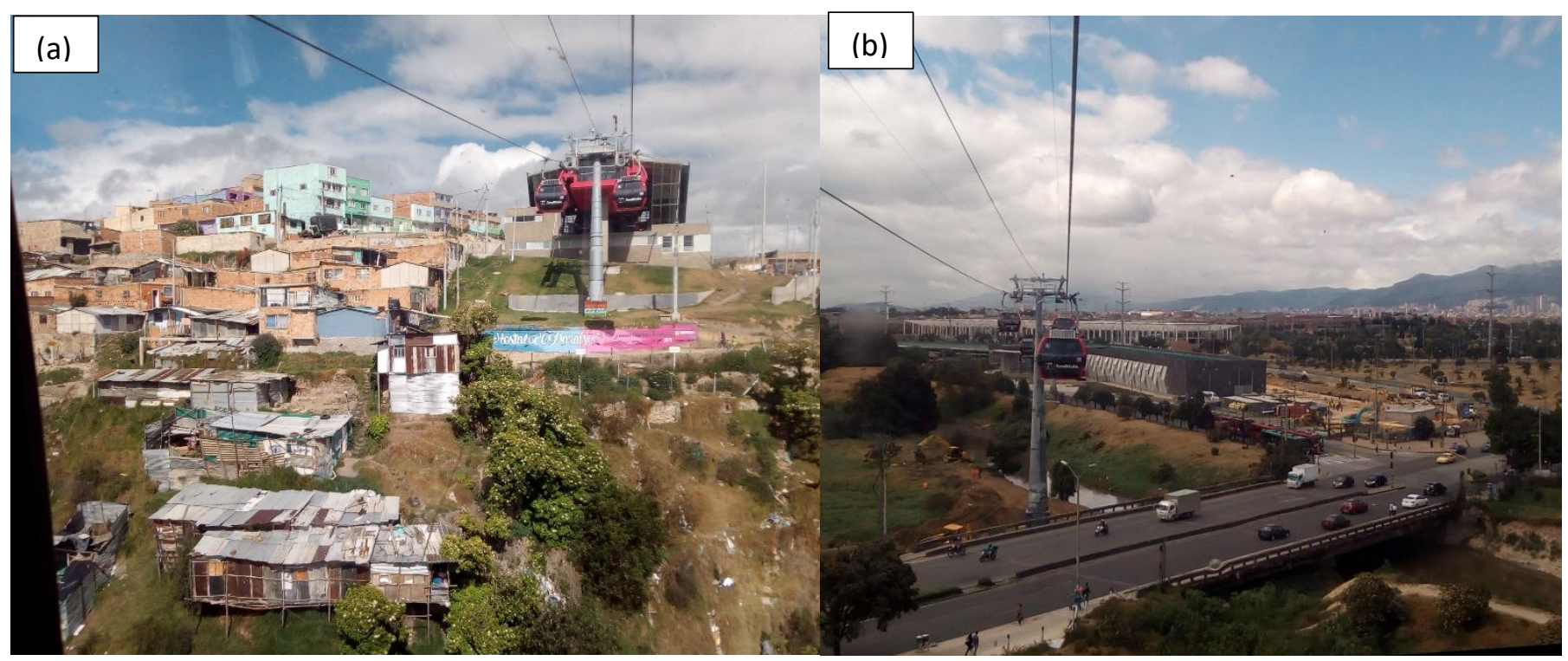

Figura 13 - (a) Estación de Transmicable y (b) Portal El Tunal. Fuente: Rubiano, M. (2019). Estación de Transmicable, barrio El Paraíso. Agosto 2019.

En promedio los residentes de Ciudad Bolívar se demoran 57,1 minutos para desplazarse a sus sitios de trabajo, lo que "la ubica como la tercera con el mayor tiempo de desplazamiento de la población ocupada" SDP (2018a, p. 67). En comparación con los resultados de la encuesta aplicada, donde en la UPZ67 El Lucero, el tiempo de viaje se redujo a 47,2 minutos en promedio, lo que representa una mejora para el 91\% de los usuarios en el tiempo de desplazamiento diario. De acuerdo con el análisis de la encuesta aplicada, se deduce que, con la implementación del Transmicable, la población residente en esta UPZ se vio beneficiada, siendo una de las localidades que se consideran con mayor densidad poblacional. La densidad poblacional de Bogotá es de 213 habitantes / hectárea, en la Localidad de Ciudad Bolívar es de 226 habitantes/hectárea y en la UPZ67, es de 335 habitantes/hectárea. Según la SDP (2018, p. 25) "las mayores densidades de población se localizan al sur y occidente de Bogotá".

Desde el análisis de las posiciones ocupacionales, en la localidad de Ciudad Bolívar, se observa una concentración de obreros y empleados domésticos según Arbeláez (2017), y, específicamente, en la UPZ67, se evidencia mayor presencia de la posición ocupacional "Sin remuneración", que corresponde, como se mencionó antes, a empleados dentro del núcleo familiar. En este sentido, se verifica que, dada esta característica, no requieren movilizarse tanto dentro de la ciudad como otros grupos representados en otras posiciones ocupacionales.

Al confrontar los resultados del cálculo del coeficiente de localización en relación al índice de segregación se puede analizar que, entendiendo que acorde con el IS que se mide entre 0 y 1 , siendo que 0 se identifica con igualdad y 1 la máxima segregación, se encuentra que de acuerdo con los datos que se muestran en la Figura 4 y en la Tabla 2, el análisis de las posiciones ocupacionales, arroja que los "obreros" son los menos segregados frente a los "Patrones" que son los más segregados, dado que los obreros tienden a residir en diferentes localizaciones de la ciudad y a interactuar con otros grupos sociales, en tanto que, los "patrones" tienden a segregarse y, autosegregarse, para no compartir con otros grupos sociales. Por otro lado, el análisis del coeficiente de localización muestra que en la UPZ67 El Lucero, la posición ocupacional más relevante corresponde a los "sin remuneración" con un índice considerable de segregación $(0,3893)$ que indica que no se tiene una movilidad cotidiana tan significativa como otras posiciones ocupacionales como los obreros, quienes están sujetos a desplazarse por la ciudad para llegar a los lugares de trabajo. De forma similar se encuentra que "los empleados domésticos" tienen un coeficiente de localización elevado $(3,53)$ en la UPZ67 y un IS de 0,2668 que indican que los empleados 
domésticos están poco segregados porque interactúan con otras posiciones ocupacionales, pero su presencia en la UPZ67 es mucho más relevante, como se esquematiza en la Figura 14.

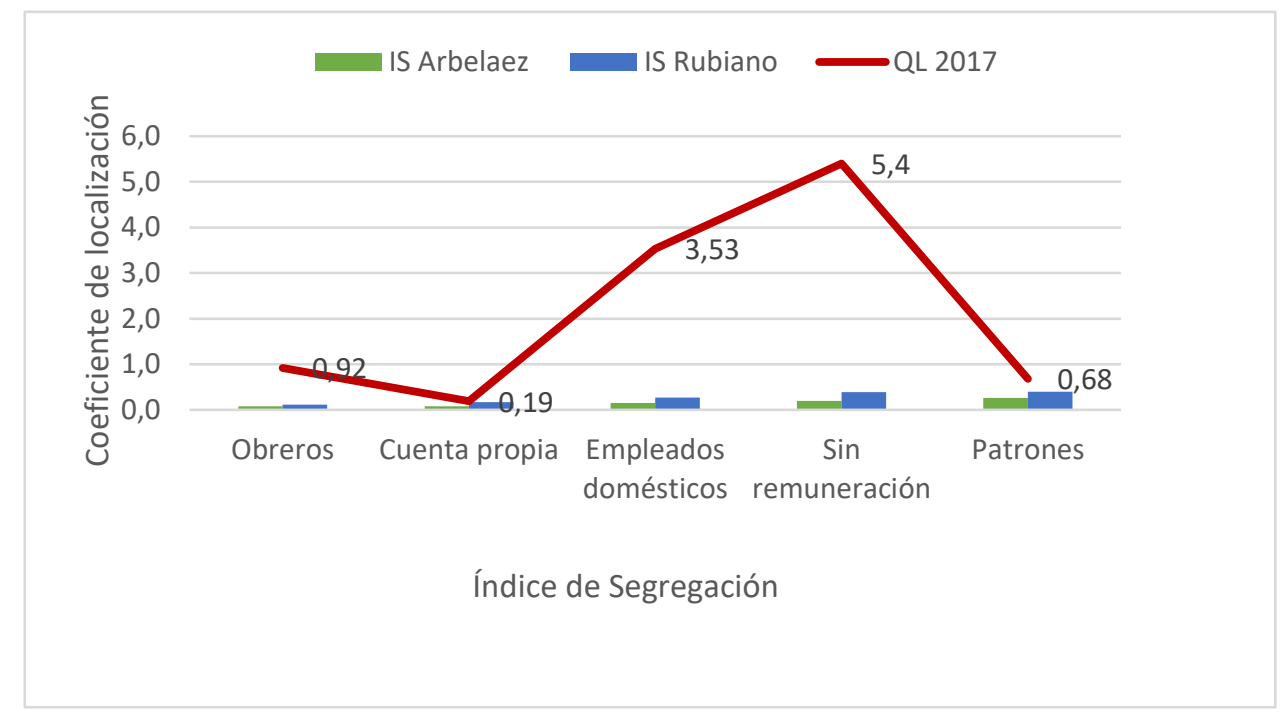

Figura 14 - Análisis Índice de segregación y Coeficiente de Segregación. Fuente: Elaboración propia.

Cuando se piensa en términos de la segregación en relación a la movilidad urbana debe considerarse que existen condiciones desiguales en el acceso a las oportunidades de bienes y servicios que se encuentran en una ciudad como Bogotá. La dificultad en la movilidad cotidiana acentúa las condiciones de segregación debido a los obstáculos para llegar hasta el lugar de trabajo, elemento que es relevante, ya que el mercado de trabajo se considera como un factor clave para determinar la desigualdad en las condiciones de vida de la población.

\section{Conclusiones}

Existen diversos enfoques para la medición de la segregación urbana, de acuerdo con la literatura existente. Sin embargo, uno de los principales retos que enfrentan los gobiernos locales es la reducción de la segregación y, especialmente, en términos de brindar mecanismos incluyentes para que la población se sienta integrada en la ciudad y, además, cuente con las condiciones de infraestructura de movilidad que requiere para movilizarse hacia el trabajo.

Como señala Soja, los urbanistas se preocupan por el desequilibrio existente entre empleo y vivienda, "una geografía mal ajustada entre vivienda asequible y oportunidades de empleo que siempre ha sido parte de la vida urbana pero que ha crecido en una proporción inusual” (Soja, 2008, p. 356). Es decir que, más allá de programas de vivienda o sistemas de transporte lo que se requiere es un programa que integre el sistema de transporte, se mejoren las condiciones de trabajo y las oportunidades para la adquisición de vivienda que esté localizada en lugares conectados fácilmente a ubicaciones donde están disponibles las oportunidades laborales.

En respuesta al planteamiento inicial sobre ¿Cómo la conformación del territorio en una ciudad como Bogotá condiciona de manera directa la forma de desplazamiento y las prácticas de la población en torno a la movilidad cotidiana y su entorno como generador de ciudadanía? Y específicamente, el interrogante sobre ¿Cuál es el diagnóstico de la segregación socio espacial en la UPZ 67 de Ciudad Bolívar? El análisis realizado buscó aportar al entendimiento del fenómeno urbano descrito en términos de la segregación espacial en cuanto al componente laboral. Se concluye que Bogotá ha presentado una expansión urbana y crecimiento demográfico, donde las localidades con mayor densidad de población se ubican en sectores con presencia de población pobre y, en este sentido, las posiciones ocupacionales que más se movilizan 
por motivos de trabajo se ubican al sur. La justificación de centrar el estudio sobre la localidad de Ciudad Bolívar y, específicamente, sobre la UPZ67 El Lucero, obedece a que en esta zona se localizó el sistema de cable aéreo Transmicable, por lo que se buscó analizar la percepción sobre la incidencia que trajo la implantación del sistema.

La UPZ67 es una de las que genera mayor cantidad de viajes diarios, lo que significa la necesidad de contar con un sistema eficiente de transporte. Adicionalmente, el coeficiente de localización en la UPZ67 mostró que la posición ocupacional "Sin remuneración" es la más presente en esta ubicación seguido de los empleados domésticos. En contraste, el índice de segregación calculado para Bogotá, evidenció que los menos segregados son los obreros, por estar repartidos por toda la ciudad en comparación con los más segregados que son los patrones o empleadores. Estos resultados denotan una conformación espacial de la ciudad donde obreros y empleados domésticos que, generalmente, residen en los barrios del sur de la ciudad y corresponden a los estratos socioeconómicos más bajos y son los que más deben movilizarse y recorrer largas distancias, lo que se corrobora con la tasa de viajes por estrato que mostró que los estratos más bajos ( 1 y 2 ) son los que más se movilizan.

Según estos hallazgos y el concepto de segregación que se acogió dentro del artículo, se evidenció la distribución desigual de los grupos sociales en el espacio urbano (Préteceille, 2006), con base en el análisis conjunto de los resultados de los índices calculados y el examen de la tasa de viajes por estrato y según motivo del viaje, lo que intenta responder a la pregunta sobre el diagnóstico de la segregación en la UPZ67, donde se localiza el Transmicable, se encontró que la UPZ, se caracteriza por concentrar una gran cantidad de población Sin remuneración y de empleados domésticos. Sin embargo, el hecho de que los obreros hayan resultado con un índice bajo de segregación, no implica que se trate de una situación positiva, pues, lo que podría entender es que, tienen una mayor tasa de viajes diarios, pero que precisamente esta información no estaba disponible a este nivel de desagregación y abre puertas para hacer mediciones orientadas a reconocer las diferencias por posiciones ocupacionales que la EM2017 no cubre.

Como se mencionó anteriormente, la movilidad urbana es un factor que condiciona el acceso a condiciones más equitativas al mercado laboral, oportunidades de educación y representa ventajas en la localización de algunos grupos sociales en comparación con otros grupos más pobres y que se ubican en lugares alejados. Por lo que, en últimas, se considera que segregación y movilidad constituyen un par dialéctico y controvertido que requiere un análisis amplio y conjunto para que los gobiernos locales puedan enfrentar estos dos fenómenos dentro de los planes de desarrollo.

Se encontró un obstáculo de tipo metodológico debido a que, en aras de mejorar la Encuesta Multipropósito que se emplea como fuente de información, cada año se ha cambiado la desagregación de los resultados, lo que dificulta la comparación y obliga a buscar otras fuentes para completar la información faltante. Dado lo reciente de la implementación de Transmicable, queda abierta la posibilidad de hacer un nuevo trabajo de campo para examinar el impacto con el desarrollo del proyecto y analizar los tiempos de desplazamiento, además, de otras dinámicas espaciales que se hayan podido generar en las zonas aledañas.

\section{Referencias}

Arbeláez, G. (2017). Mutaciones socioespaciales en la segregación laboral en la zona metropolitana. In Alfonso, Ó., Bogotá en la encrucijada del desorden: estructuras socioespaciales y gobernabilidad metropolitana (p. 427-461). Bogotá: Universidad Externado de Colombia.

Beuf, A., \& García, C. (2016). La producción de vivienda social en Colombia: un modelo en tensión. In P. Abramo, M. Rodríguez Mancilla, \& J. Erazo Espinosa (Coords.), Procesos urbanos en acción (v. 3, p. 393-421). Buenos Aires: CLACSO.

Castells, M. (2014). La Cuestión Urbana. (15a ed.). Madrid: Siglo XXI Editores.

urbe. Revista Brasileira de Gestão Urbana, 2020, 13, e20190372 
Colombia. Alcaldía Mayor de Bogotá. (2004, 22 de junio). Decreto 190 de 2004. Por medio del cual se compilan las disposiciones contenidas en los decretos distritales 619 de 2000 y 469 de 2003. Bogotá: Registro Distrital No. 3122.

Departamento Administrativo Nacional de Estadística - DANE (2020). Boletín Desempleo febrero 2020. Recuperado el 19 de marzo de 2020, de https://www.dane.gov.co/files/investigaciones/boletines/ech/ech/pres_web_empleo_resultados_feb_20.pdf

Departamento Administrativo Nacional de Estadística - DANE (2019). Censo Nacional de Población y Vivienda. Recuperado el 15 de febrero de 2020, de https://www.dane.gov.co/index.php/estadisticas-por-tema/demografia-ypoblacion/censo-nacional-de-poblacion-y-vivenda-2018

Departamento Administrativo Nacional de Estadística - DANE (2018). Encuesta Multipropósito 2017. Recuperado el 19 de noviembre de 2019, de http://microdatos.dane.gov.co/index.php/catalog/565/get_microdata

Departamento Administrativo Nacional de Estadística - DANE (2015). Metodología de estratificación socioeconómica urbana para la prestación de servicios públicos domiciliarios. Enfoque Conceptual. Recuperado el 19 de noviembre de 2019, de https://www.dane.gov.co/files/geoestadistica/estratificacion/EnfoqueConceptual.pdf

Fresneda, O., Reyes, J., Pinzón, L. M., Naranjo, A., Quintero, J., \& Sabogal, A. (2016). Caracterización y medición de la segregación social y escolar en Bogotá y la región. In Secretaría Distrital de Planeación, La estratificación en Bogotá: impacto social y alternativas para asignar subsidios (p. 61-180). Secretaría Distrital de Planeación: Bogotá.

Jans, M. (2017). Movilidad urbana: en camino a sistemas de transporte colectivo integrados. AUS [Arquitectura/Urbanismo/Sustentabilidad], (6), 6-11. Recuperado el 25 de marzo de 2020, de http://revistas.uach.cl/pdf/aus/n6/art02.pdf

Linares, S., \& Lan, D. (2007). Análisis multidimensional de la segregación socioespacial en Tandil (Argentina), aplicando SIG. Recuperado el 15 de octubre de 2019 de https://bit.ly/3pI2Tqg

Litman, T. (2008). Evaluating accessibility for transportation planning. Victoria, Canada: Victoria Transport Policy Institute. Recuperado el 8 de febrero de 2020, de https://azdhs.gov/documents/prevention/nutrition-physicalactivity/nutrition-physical-activity-obesity/healthy-communities/accessibility-transportation-planning.pdf

Moreno Luna, C.A. (2017). Pobreza y Movilidad Cotidiana. Realidades en Bogotá y Soacha, Colombia. (Tesis de doctorado). Universidad Autónoma de Barcelona, Barcelona. Recuperado el 25 de octubre de 2019, de https://ddd.uab.cat/pub/tesis/2017/hdl_10803_458686/caml1de1.pdf

Moreno Luna, C. A., \& Rubiano Bríñez, M. (2014). Segregación residencial y movilidad cotidiana en el contexto metropolitano. Un estudio a partir de las relaciones Bogotá-Soacha. Territorios, (31), 133-162. https://doi.org/10.12804/territ31.2014.06

Préteceille, E. (2006). La ségrégation sociale a-t-elle augmenté? Sociétés contemporaines, (2), 69-93.

Rubiano-Bríñez, M., \& Eligio-Triana, C. (2019). Regiones administrativas y de planificación: análisis comparativo de las primacías urbanas en la RAPE Región Central y RAP Pacífico. urbe. Revista Brasileira de Gestão Urbana, 11 , e20180107. https://doi.org/10.1590/2175-3369.011.e20180107

Salas, M. M., \& Solano, F. (1993). Segregación urbana: un acercamiento conceptual. Revista de ciencias sociales, (61), 1726.

Secretaría Distrital de Movilidad (2017). Observatorio de Movilidad de Bogotá D.C/2017. Bogotá.

Secretaría Distrital de Planeación. (2018). Análisis demográfico y proyecciones poblacionales de Bogotá. Análisis demográfico y proyecciones poblacionales de Bogotá. Bogotá: Secretaría Distrital de Planeación. Recuperado el 25 de octubre de 2019, de http://www. sdp. gov. co/sites/default/files/demografia_proyecciones_2017_0_0. pdf.

Secretaría Distrital de Planeación. (2018a). Monografía Localidad Ciudad Bolívar 2017. Bogotá: Secretaría Distrital de Planeación.

Secretaría Distrital de Planeación. (2016). La estratificación en Bogotá: impacto social y alternativas para asignar subsidios. Bogotá: Secretaría Distrital de Planeación.

Secretaría Distrital de Planeación. (2012). Bogotá Ciudad de Estadísticas, Boletín n. 39: Segregación socioespacial en Bogotá 2011. Indicadores y Medición. Bogotá: Secretaría Distrital de Planeación. 
Soja, E. W. (2008). Postmetrópolis: estudios críticos sobre las ciudades y las regiones (V. Hendel, \& M. Cifuentes, Trans.). Madrid: Traficantes de Sueños. Recuperado el 10 de noviembre de 2018, de https://www.traficantes.net/sites/default/files/pdfs/Postmetrópolis-TdS.pdf

Transmilenio. (2013). Historia de Transmilenio. Recuperado el 20 de noviembre de 2019, de https://www.transmilenio.gov.co/publicaciones/146028/historia-de-transmilenio/

Editor: Fábio Duarte

Recibido: 16 Dic. 2019

Aprobado: 05 Oct. 2020 